EXTENDED REPORT

\title{
Optic nerve compression by normal carotid artery in patients with normal tension glaucoma
}

\author{
N Ogata, M Imaizumi, H Kurokawa, M Arichi, M Matsumura
}

Br J Ophthalmol 2005;89:174-179. doi: 10.1136/bjo.2004.047035

See end of article for authors' affiliations

Correspondence to Nahoko Ogata, MD, PhD, Department of

Ophthalmology Kansai

Medical University, 10-15

Fumizono-cho, Moriguchi,

Osaka 570-8507, Japan:

ogata@takii.kmu.ac.jp

Accepted for publication 7 July 2004

\begin{abstract}
Aim: To determine whether compression of the optic nerve by the intracranial carotid artery (ICA) can be a causative factor of normal tension glaucoma (NTG).

Methods: The medical records of 103 eyes of 54 Japanese patients with NTG and 104 eyes of 52 age matched control patients were reviewed. The neuroradiological findings of magnetic resonance images (MRI) were evaluated to determine the relation between the optic nerve and ICA. The clinical characteristics and general medical conditions, such as diabetes and systemic hypertension, were also compared between the two groups.

Results: The prevalence of optic nerve compression by the ICA in patients with NTG was $49.5 \%$, which was significantly higher than that in control group with $34.6 \%(p=0.035)$. Bilateral compression of the optic nerve was detected in 22 patients with NTG $(40.7 \%)$, and this was also significantly higher $(p=0.029)$ than that in the control group (11 patients, 21.2\%). In the NTG group, eyes with cup/disc ratio (C/D ratio) $\geqslant 0.7$ showed a higher percentage of compression (52.6\%) compared with eyes with C/D ratio of $<0.7$ $(12.5 \% ; p=0.042)$. The presence of diabetes and hypertension did not affect the incidence of optic nerve compression by ICA significantly.

Conclusions: The significantly higher percentage of NTG patients who had optic nerve compression by the ICA suggests that compression of the optic nerve by ICA may be a possible causative factor or a risk factor for optic nerve damage in some patients with NTG.
\end{abstract}

$\mathrm{T}$ he term, normal tension glaucoma (NTG), is used for patients with typical glaucomatous damage of the optic nerve head and visual field loss in spite of normal intraocular pressure (IOP). ${ }^{12}$ Various mechanisms have been proposed to explain the origin of NTG-for example, vascular insufficiency, decreased optic disc resistance, and intraocular pressure effects, ${ }^{2-6}$ but the exact cause of NTG has still not been conclusively determined.

Factors other than IOP also seem to be involved in the development of glaucomatous optic neuropathy in at least some eyes with NTG. Included as positive factors are a higher incidence of disc haemorrhage, ${ }^{238}$ more pronounced peripapillary atrophy, ${ }^{9}$ higher incidence of retinal occlusive vascular diseases, ${ }^{2}{ }^{10}$ coexistence of immunocompromised conditions, ${ }^{11} 12$ increased resistance index in orbital vessels, ${ }^{13}$ and alterations in the diurnal variation of systemic blood pressure. $^{14} 15$

It is generally accepted that high or even normal intracranial blood pressure can cause dysfunction of cranial nerves when a blood vessel is situated where it can compress the nerve. ${ }^{16-18}$ The occurrence of such compressive damage to the optic nerve is poorly recognised, even though several studies have shown that the optic nerves can be damaged by vascular compression. ${ }^{19-24}$

Optic nerve compression by the intracranial carotid arteries (ICA) has been suggested to be a cause of visual field defects in patients with optic neuropathy, ${ }^{19}{ }^{2022-25}$ and in patients with NTG. ${ }^{26-28}$ The purpose of this study was to examine in more detail whether the compression of the optic nerve by the ICA can be a possible causative factor of NTG

\section{PATIENTS AND METHODS}

This study was conducted to conform to the tenets of the Declaration of Helsinki, and informed consent was obtained from all patients after an explanation of the purpose and procedures of the study.
Fifty four consecutive patients with NTG who were diagnosed at the Kansai Medical University Hospital or at the Saiseikai Izuo Hospital, Osaka, Japan, were studied. We defined NTG as the presence of typical glaucomatous optic nerve head changes-for example, optic disc cup, neural rim saucerisation, or notching in the inferior or superior-temporal disc areas; glaucomatous nerve fibre layer defects on visual field testing (that is, nasal step, or paracentral, Seidel's, or arcuate scotoma); and an intraocular pressure never above $21 \mathrm{~mm} \mathrm{Hg}$ on initial or follow up examinations. ${ }^{129}$ All patients who met the criteria of NTG and agreed to have laboratory examinations and magnetic resonance imaging (MRI) imaging were studied.

The mean age of the 54 patients with NTG was 69 (SD 11) years with a range of 43-92 years. We excluded patients with significant retinal diseases, with media opacity preventing adequate examination of the posterior pole, and with other diseases that could cause a decrease of visual function (determined by clinical judgment and laboratory investigations). None of the patients had intracranial abnormalities such as tumours, aneurysms, or brain infarctions involving the anterior visual pathways.

In the 108 eyes of 54 patients with NTG (28 men and 26 women), three patients had unilateral NTG. Of these three patients, the three fellow eyes with no visual fields defects were excluded from the NTG group. One eye with a small optic disc and another with macular degeneration were excluded from the NTG group. Thus, a total of 103 eyes of 54 patients were placed in the NTG group. The fellow eyes of the three patients with unilateral NTG were placed in the fellow eye group for evaluation.

Abbreviations: C/D ratio, cup/disc ratio; ICA, intracranial carotid artery; MRI, magnetic resonance imaging; NTG, normal tension glaucoma 


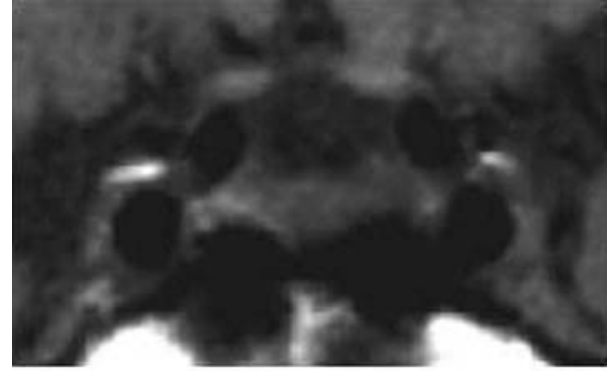

Grade 0

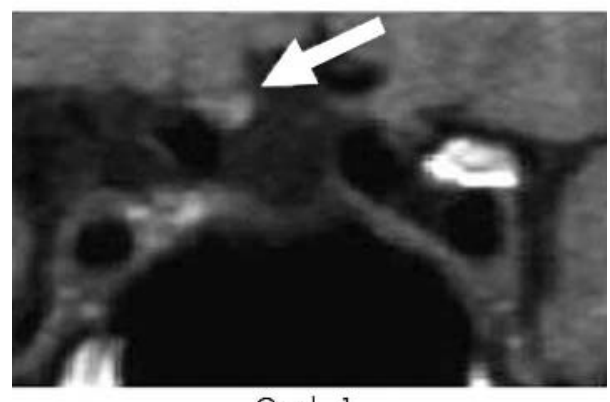

Grade 1

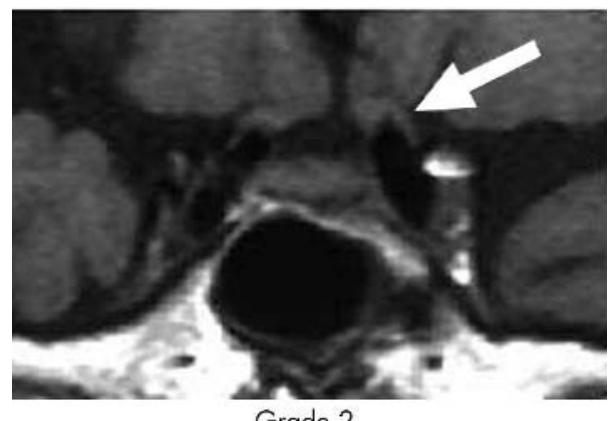

Grade 2

Figure 1 The grading scheme of $\mathrm{Tl}$ weighted MRI sequences acquired in the coronal plane. The relation between the optic nerve and the adjacent intracranial carotid artery (ICA) was classified into three grades as described in text. Top image shows no optic nerve compression and was graded as 0 . Middle image shows slight optic nerve compression and was graded as 1.0. Bottom image shows marked optic nerve compression and was graded as 2.0 .

The visual acuity, optic disc head cupping, and laboratory tests for diabetes mellitus and systemic hypertension were determined for all patients diagnosed with NTG. All of the patients had normal findings for complete blood cell counts, serological test for syphilis, and sedimentation rate.

The control group was made up of 104 eyes of 52 age matched patients ( 22 men and 30 women, ages $41-88$ years; average 68.0 ( SD 14) years). These patients had consulted the Department of Internal Medicine in Saiseikai Izuo Hospital and had undergone MRI for a screening checking up. None of the control patients had a known ocular or neurological condition that might affect the visual pathways before the imaging. In addition, dilated ocular evaluations showed no signs of visual pathway disease.

MRI (Philips Co, Gyo Scan ACS-NT PT 3000) was performed at the initial examination, and from our experience, Tl weighted MRI sequences acquired in the coronal plane were taken as they were the optimal images to evaluate the anatomical relation between the intracranial optic nerve and the ICA. Radiological analysis was made by two experienced radiologists who were informed of the age and sex but were masked as to whether the patient was in the NTG or control group.

The relation between the optic nerve and the adjacent ICA was designated by the following grading scheme: grade 0 , no contact or contact but without distortion of the optic nerve contour (contact but no compression); grade 1, contact with slight distortion of the optic nerve contour (slight compression); grade 2, contact with moderate or severe distortion of the optic nerve contour (moderate to severe compression; fig l).

The medical records and MRI evaluation of all patients were reviewed. Categorical data were summarised as percentages, and statistical analysis of the MRI evaluations between groups was compared with $\chi^{2}$ tests. $p$ Values less than 0.05 were considered to be significant.

\section{RESULTS}

\section{NTG versus control}

Of the 103 eyes of 54 patients with NTG, compression of the optic nerve was observed in 51 (49.5\%) of the eyes and not observed in $52(50.5 \%)$ of the eyes. In the 51 eyes with optic nerve compression, 33 eyes were classified as grade $1(64.7 \%)$

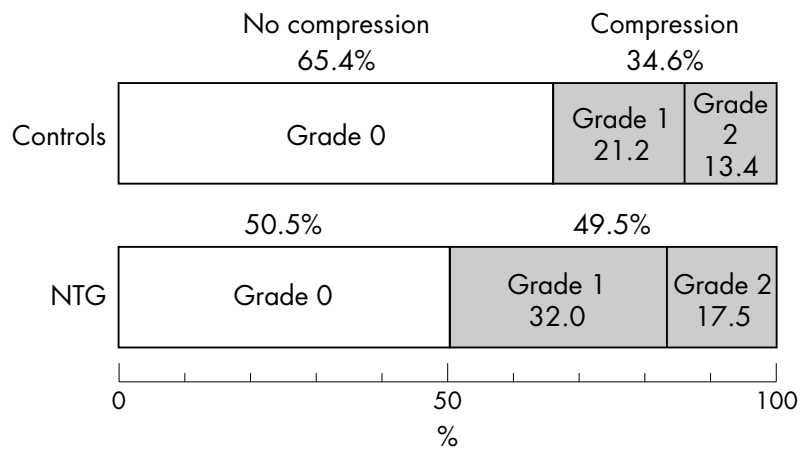

Figure 2 Frequency of optic nerve compression by ICA. Of the 103 eyes of 54 patients with NTG, compression of the optic nerve was observed in 51 eyes (49.5\%) and not observed in 52 eyes (50.5\%). In the 51 eyes with optic nerve compression, 33 eyes were classified as grade 1 (32.0\%) and 18 eyes as grade 2 (17.5\%). In the 104 eyes of 52 control patients, compression was observed in 36 eyes $(34.6 \%)$ and not observed in 68 eyes $(65.4 \%)$. In the 36 eyes with optic nerve compression, 22 eyes were classified as grade $1(21.1 \%)$ and 14 eyes as grade 2 (13.5\%). The percentage of eyes with compression of the optic nerve was significantly higher in the eyes with NTG than that in the control group $\left(\chi^{2}=4.4, p=0.035\right)$. The percentage of eyes with grade 2 compression in the NTG group was not significantly higher than that in control group $\left(\chi^{2}=1.6, p=0.20\right)$.

Table 1 The frequency of the compression of optic nerve by ICA

\begin{tabular}{|c|c|c|c|c|c|c|}
\hline & \multirow{2}{*}{$\begin{array}{l}\text { Number of } \\
\text { patients }\end{array}$} & \multirow{2}{*}{$\begin{array}{l}\text { Number of } \\
\text { eyes }\end{array}$} & \multirow{2}{*}{$\begin{array}{l}\text { No Compression } \\
\text { Grade } 0(\%)\end{array}$} & \multicolumn{3}{|c|}{ Compression (\%) } \\
\hline & & & & & Grade 1 & Grade 2 \\
\hline Control & 52 & 104 & $68(65.4 \%)$ & $36(34.6 \%)$ & $22(61.1 \%)$ & $14(38.9 \%)$ \\
\hline NTG & 54 & 103 & $52(50.5 \%)$ & $51(49.5 \%)$ & 33 (64.7\%) & 18 (35.3\%) \\
\hline
\end{tabular}


Table 2 Frequency of bilateral optic nerve compression by ICA

\begin{tabular}{lllll}
\hline & $\begin{array}{l}\text { Number of } \\
\text { patients }\end{array}$ & $\begin{array}{l}\text { No compression in } \\
\text { both eyes }(\%)\end{array}$ & $\begin{array}{l}\text { Unilateral compression } \\
(\%)\end{array}$ & $\begin{array}{l}\text { Bilateral compression } \\
(\%)\end{array}$ \\
\hline Controls & 52 & $27(51.9)$ & $14(26.9)$ & $11(21.2)$ \\
NTG & 54 & $23(42.6)$ & $9(16.7)$ & $22(40.7)$ \\
\hline NTG, normal tension glaucoma. & &
\end{tabular}

and 16 eyes as grade $2(35.3 \%)$. In the 104 eyes of 52 control patients, compression was observed in 36 eyes $(34.6 \%)$ and not observed in 68 eyes $(65.4 \%)$. In the 36 eyes with optic nerve compression, 22 eyes were classified as grade 1 (61.1\%) and 14 eyes as grade $2(38.9 \%$; table 1$)$. The percentage of eyes with compression of the optic nerve was significantly higher in the eyes with NTG than that in the control group $\left(\chi^{2}=4.4, p=0.035\right.$; fig 2$)$. The percentage of eyes with grade 2 compression was not significantly higher in the NTG group than that in the control group $\left(\chi^{2}=1.6, p=0.20\right.$; fig 2$)$.

In the three patients with unilateral NTG, compression was observed in one of the fellow eyes and not observed in two eyes. Because the number of eyes in the unilateral NTG group was small, it was difficult to compare the frequency of the optic nerve compression to the other groups statistically.

\section{Bilateral and unilateral compression}

In the 54 patients with NTG, 22 patients (40.7\%) had bilateral compression of the optic nerves by the ICA, nine patients (16.7\%) had unilateral compression, and optic nerve compression was not found in either eye in 23 patients $(42.6 \%)$. Of the 52 patients in the control group, only 11 patients had bilateral optic nerve compression (21.2\%), 14 patients $(26.9 \%)$ had unilateral compression, and 27 patients $(61.9 \%)$ had no compression. The prevalence of bilateral optic nerve compression was significantly higher in NTG group than that in the control group $\left(\chi^{2}=4.74, \mathrm{p}=0.029\right.$, table 2).

\section{Optic disc cupping}

In the 103 eyes in the NTG group, there were 95 eyes (93.2\%) with a C/D ratio $\geqslant 0.7$, and in this group, there were 50 eyes $(52.6 \%)$ with compression of the optic nerve by the ICA. Of the eight eyes with $\mathrm{C} / \mathrm{D}$ ratio $\leqslant 0.7$, only one eye $(12.5 \%)$ had a compression of the optic nerve by the ICA. The higher percentage of eyes with $\mathrm{C} / \mathrm{D}$ ratio $<0.7$ who showed compression was statistically different from eyes with $\mathrm{C} / \mathrm{D}$ ratio $<0.7\left(\chi^{2}=5.7, \mathrm{p}=0,017\right.$; and $\chi^{2}=4.1, \mathrm{p}=0,042$ with Yates's correction). None of the eyes in the control group had a $\mathrm{C} / \mathrm{D}$ ratio $\geqslant 0.7$ (table 3 , fig 3 ).
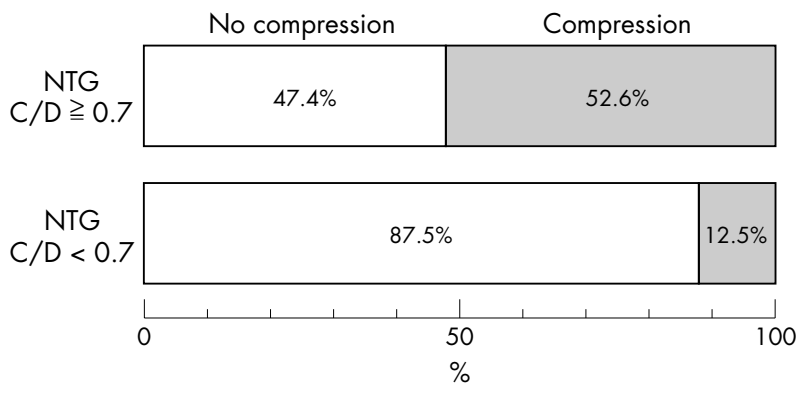

Figure 3 Frequency of optic nerve compression and disc cupping in NTG. The compression of optic nerve by ICA was found in $52.6 \%$ of eyes with $C / D$ ratio $\geqslant 0.7$, and in $12.5 \%$ of the eyes with $C / D<0.7\left(\chi^{2}=4.1\right.$, $p=0,042$ ).

\section{Patients with diabetes mellitus}

There were 34 eyes of 17 patients with diabetes mellitus $(32.7 \%)$ in the control group, and of these, optic nerve compression was observed in 11 eyes $(32.4 \%)$ and not observed in 23 eyes $(67.6 \%)$. Of the 70 eyes of 35 patients without diabetes in the control group, compression was observed in 25 eyes $(35.7 \%)$ and compression was not observed in 45 eyes $(64.3 \%)$. The difference in the percentage of eyes with optic nerve compression in the two groups was not significantly different $\left(\chi^{2}=0.11, \mathrm{p}=0,32\right.$, table 3$)$.

In NTG group, there were 14 eyes of seven patients with diabetes mellitus (13.6\%) and 89 eyes of 47 patients without diabetes mellitus (86.4\%). Of the 14 eyes of the NTG patients with diabetes, compression of the optic nerve was observed in four eyes $(36.4 \%)$ and not observed in 10 eyes (63.6\%). Of the 89 eyes of non-diabetic patients in the NTG group, compression was observed in 47 eyes $(52.8 \%)$ and not observed in 42 eyes (47.9\%). The difference between patients with and without diabetes in NTG was not significant $\left(\chi^{2}=1.96, p=0.16\right.$, table 4$)$.

\section{Patients with systemic hypertension}

In the controls, there were 30 patients with hypertension (57.7\%) and 22 patients (42.3\%) without hypertension. Of the 60 eyes of 30 patients with hypertension, compression was observed in 22 eyes $(36.7 \%)$ and not observed in 38 eyes $(63.3 \%)$, and of the 44 eyes of 22 patients without hypertension, compression was observed in 14 eyes $(31.8 \%)$ and not observed in 30 eyes $(68.2 \%)$. The difference in the percentage of eyes with compression in the control group with or without hypertension was not significantly different $\left(\chi^{2}=0.26, p=0.61\right.$, table 3$)$.

In NTG group, there were 32 eyes of 17 patients with hypertension $(31.5 \%)$ and 71 eyes of 37 patients without hypertension $(68.5 \%)$. Of the 32 eyes of patients with hypertension, optic nerve compression was observed in 15 eyes $(46.9 \%)$ and not observed in 17 eyes $(53.1 \%)$, and of the 71 eyes of without hypertension, compression was observed in 36 eyes $(50.7 \%)$ and not observed in 35 eyes (49.3\%). The difference in the percentage of eyes with compression between patients with and without hypertension in the NTG group was not significant $\left(\chi^{2}=0.16, p=0.69\right.$, table 4$)$.

\section{DISCUSSION}

A compression of the optic nerve by normal carotid arteries has been suggested to be a possible cause of visual field defects in patients with optic neuropathy ${ }^{19} 20^{22-25}$ and with NTG. ${ }^{26-28}$ Jacobson $e t ~ a l^{30}$ used MRI to show that an anatomic compression of the intracranial optic nerve by the ICA occurred relatively frequently in asymptomatic patients; contact of one or both optic nerves in 70 of 100 asymptomatic patients; bilateral compression in 12 of 100; and unilateral compression in five of 100 asymptomatic patients. Although we did not classify cases that only showed a contact of the optic nerve by the ICA into the compression group, we found an anatomic compression of the optic nerve by ICA in 36 eyes of 104 optic nerves $(34.6 \%)$ in 52 control patients. Of these, only 11 patients showed bilateral compression $(21.2 \%)$ and 19 patients $(26.9 \%)$ showed unilateral compression. This ratio of optic nerve compression is higher than that 
Table 3 Optic disc cupping and the frequency of optic nerve compression in NTG

\begin{tabular}{llll}
\hline NTG & $\begin{array}{l}\text { Number of } \\
\text { eyes }\end{array}$ & $\begin{array}{l}\text { No compression } \\
(\%)\end{array}$ & $\begin{array}{l}\text { Compression } \\
(\%)\end{array}$ \\
\hline $\begin{array}{l}\text { Eyes with a C/D } \\
\text { ratio } \geqslant 0.7\end{array}$ & 95 & $45(47.4 \%)$ & $50(52.6 \%)$ \\
$\begin{array}{l}\text { Eyes with C/D } \\
\text { ratio }<0.7\end{array}$ & 8 & $7(87.5 \%)$ & $1(12.5 \%)$ \\
\hline C/D ratio, cup/disc ratio; NTG, normal tension glaucoma. & \\
\hline
\end{tabular}

reported. ${ }^{30}$ The difference may depend on the neuroimaging technique or the type of controls, because our control patients were relatively old.

Compressive optic neuropathy is usually related to aneurysms, meningiomas, or other types of tumours. ${ }^{31-33}$ These mass lesions are invasive and can grow quickly to induce damage of the optic nerve, but compression of the optic nerve by normal ICA is usually slow and non-invasive. Thus, the patients with optic nerve compression in the control group may be asymptomatic.

Compressive optic neuropathy is usually caused by intracranial lesions and not by normal blood vessels, ${ }^{22}{ }^{33}$ although neuropathies of the trigeminal, facial, and abducens nerves caused by compression by normal blood vessels have been described.$^{16-18}$ Nishioka et al reported a case whose visual function was improved by surgical release of a compression of the optic nerve from normal ICA. ${ }^{19}$ These findings support the concept that the optic nerves can be damaged by the compression of normal appearing ICAs that do not show artherosclerotic or aneurysmal changes.

Gutman et $a^{26}$ studied the computed tomographic (CT) scans of 62 patients with NTG and found that $90 \%$ of the patients had either calcification or dilatation of the ICA adjacent to the intracranial opening of the optic canal, whereas only $21 \%$ of 24 age matched controls had similar abnormalities. Thus, they suggested that these abnormal ICAs were causing compressive optic nerve damage resulting in the optic nerve head cupping. On the other hand, Stroman et $a l^{27}$ studied 20 patients with NTG using MRI to determine the cause of optic nerve damage and reported that no difference was found in either the distance between the ICA and optic nerve or in the area of the ICA that showed an absence of blood flow in the patients with NTG compared with age matched controls. Thus, the role of compression of the optic nerve by the ICA in patients with NTG is still not certain.

Our data showed that the percentage of eyes with compression of the optic nerve by ICA was significantly higher in eyes with NTG $(49.5 \%)$ than that in controls $(34.6 \%)$. In addition, bilateral compression occurred in $40.7 \%$ of the patients with NTG, whereas bilateral optic nerve compression was detected in only $21.2 \%$ of the control group. This difference was also statistically significant.

Earlier, Umihara et al studied 16 patients with NTG and 16 patients with high tension glaucoma. ${ }^{28}$ They reported that compression of the optic nerve by the ICA was found in 24 $(75 \%)$ of 32 optic nerves and bilateral compression was observed in 12 NTG patients. In the patients with high tension glaucoma, compression of the optic nerve by the ICA was found in $12(37.5 \%)$ of 32 optic nerves and bilateral compression occurred in only three patients. Our findings are comparable to these values, and the values support our hypothesis that optic nerve compression by the ICA can be a possible cause of NTG in some patients.

Additional support of our hypothesis was the finding of a higher percentage $(52.6 \%)$ of optic nerve compression in NTG eyes with $\mathrm{C} / \mathrm{D}$ ratio $\geqslant 0.7$ than in eyes with $\mathrm{C} / \mathrm{D}$ ratio $<0.7$ $(12.5 \%)$. The difference was statistically significant and indicated that optic nerve compression by ICA may contribute the optic disc damage or at least may be a risk factor. It is widely accepted that the C/D ratio is correlated with the severity of visual field defect, and alterations of the $\mathrm{C} / \mathrm{D}$ ratio can be detected by biomicroscopy. The $\mathrm{C} / \mathrm{D}$ ratio is not affected by the condition of the patients, such as those with cataracts. However, a previous report could not find significant differences in visual field variables in NTG patients with or without compression, ${ }^{28}$ therefore additional studies are necessary to determine the relation between optic nerve compression and severity of visual field defects.

It should be emphasised that our data do not directly indicate that neurosurgical procedures to decompress the optic nerve by $\mathrm{ICA}^{20-22}$ should be performed in all patients with NTG, because almost a half of NTG patients $(50.5 \%)$ did not have a compression of the optic nerve, and control patients with compression of optic nerve are asymptomatic. Thus, additional studies with long term follow up will be necessary to determine how optic nerve compression is contributing to the optic neuropathy in NTG and in the prognosis of NTG, because an aetiological association is still unknown.

Compressive optic neuropathy and atypical glaucoma are two conditions with clinical profiles that have overlapping

Table 4 Frequency of the compression of optic nerve by ICA in patients with DM and HT

\begin{tabular}{lllll}
\hline & $\begin{array}{l}\text { Number of } \\
\text { patients }\end{array}$ & $\begin{array}{l}\text { Number of } \\
\text { eyes }\end{array}$ & $\begin{array}{l}\text { Number of eyes without } \\
\text { compression (\%) }\end{array}$ & $\begin{array}{l}\text { Number of eyes with } \\
\text { compression (\%) }\end{array}$ \\
\hline Control & 52 & 104 & $68(65.4)$ & $36(34.6)$ \\
Without diabetes & 35 & 70 & $45(64.3)$ & $25(35.7)$ \\
With diabetes & 17 & $34(32.7 \%)$ & $23(67.6)$ & $11(32.4)$ \\
Without HT & 22 & 44 & $30(68.2)$ & $14(31.8)$ \\
With HT & 30 & $60(57.7 \%)$ & $38(63.3)$ & $22(36.7)$ \\
NTG & 54 & 103 & $52(50.5)$ & $51(49.5)$ \\
Without diabetes & 47 & 89 & $42(47.2)$ & $47(52.8)$ \\
With diabetes & 7 & $14(13.6 \%)$ & $10(71.2)$ & $4(28.9)$ \\
Without HT & 37 & 71 & $35(49.3)$ & $36(50.7)$ \\
With HT & 17 & $32(31.5 \%)$ & $17(53.1)$ & $15(46.9)$ \\
\hline
\end{tabular}

DM, diabetes mellitus; NTG, normal tension glaucoma; $H T$, hypertension. 
characteristics in some of the reported patients. ${ }^{19} 232532-34$ Patients with compressive optic neuropathy show loss of central acuity associated with relative central and caecocentral scotomas. While it is possible and common for these patients to present with additional arcuate visual field defects, and some patients have nerve fibre bundle visual field defects minimising the potential for diagnostic confusion between the two disorders, most patients have additional signs atypical for glaucoma, including a decrease of visual acuity, abnormal colour vision, a central scotoma, and pallor of the neuroretinal rim, and the finding of increased cupping is unusual. ${ }^{23} 313335$

Systemic hypertension and diabetes are major causes of vascular dysfunction. ${ }^{36-38}$ However, the presence of diabetes or hypertension in patients with NTG did not alter the percentage of cases with compression of the optic nerve by the ICA. In the control group, the percentage of cases with systemic hypertension and diabetes was relatively higher because the patients had been treated at the Department of Internal Medicine. Although this may have biased the findings in the controls, this did not affect the percentages of optic nerve compression by the ICA.

Although neuroimaging studies have been recommended to be performed in the diagnostic evaluation of patients with $\mathrm{NTG}^{29}$ most patients with NTG do not routinely undergo neuroimaging, and only those who are judged to be atypical (for example, poor correlation between the pattern or amount of visual field loss and optic disc cupping) or are at a high risk of having an intracranial mass are examined. In this study, none of the patients diagnosed with NTG had neuroradiological evidence of an intracranial mass lesion involving the anterior visual pathways, even though there have been several reports of the high prevalence of intracranial mass lesions in patients with NTG. ${ }^{35} 3739$ More recently, it was reported that $6.5 \%$ patients with NTG have clinically relevant intracranial compressive lesions involving the anterior visual pathway. ${ }^{40}$ While some have advocated obtaining neuroimaging in patients with NTG, ${ }^{26}{ }^{40}$ Greenfield et al suggested that routine neuroimaging may be of little value because of its low sensitivity for detecting such lesions. ${ }^{35}$ The high spatial resolution and multiplaner imaging capability of CT scan, and the more recent MRI techniques, provide the clinician with non-invasive ways to evaluate the intracranial mass and the relation between the ICA and optic nerve. Although the cost-benefit ratio of performing such studies is still unknown, but weighing the financial implications against the improved quality of life, neuroimaging of NTG patients should be consided.

In conclusion, our study demonstrated that the frequency of compression of the optic nerve by ICA and also bilateral optic nerve compression in eyes with NTG was significantly higher than in the control group. These differences suggest that optic nerve compression by ICA may be one of the possible causes or may be a risk factor for optic nerve damage of NTG in some patients.

\section{ACKNOWLEDGEMENTS}

This study was supported in part by a grant in aid for scientific research from the Ministry of Education in Japan and by the Japan Association for Inhibition of Blindness.

\section{Authors' affiliations}

N Ogata*, M Imaizumi*, M Arichi, M Matsumura, Department of Ophthalmology, Kansai Medical University, Moriguchi, Osaka, Japan H Kurokawa*, Department of Radiology, Osaka Saiseikai Izuo Hospital, and Department of Radiology, Kansai Medical University, Moriguchi, Osaka, Japan

*These authors contributed equally to this manuscript.

\section{REFERENCES}

1 Stewart WC. Clinical practice of glaucoma. Thorofare, NJ: Slack Inc, 1990:129-48.

2 Levene RZ. Low tension glaucoma: a critical review and new material. Surv Ophthalmol 1980;24:621-64.

3 Drance SM, Sweeney VP, Morgan RW, et al. Studies of factors involved in the production of low tension glaucoma. Arch Ophthalmol 1973;89:457-65.

4 Phelps CD, Corbett JJ. Migraine and low-tension glaucoma: a case-control study. Invest Ophthalmol Vis Sci 1985;26:1 105-8.

5 Drance SM, Douglas GR, Wijsman K, et al. Response of blood flow to warm and cold in normal and low-tension glaucoma patients. Am J Ophthalmol $1988 ; 105: 35-9$.

6 Zeiter JH, Shin DH, Juzych MS, et al. Visual field defects in patients with normal tension glaucoma and patients with high-tension glaucoma. Am J Ophthalmol 1992;114:758-63.

7 Gloster J. Incidence of optic disc haemorrhages in chronic simple glaucoma and ocular hypertension. Br J Ophthalmol 1981;65:452-6.

8 Kitazawa Y, Shirato S, Yamamoto T. Optic disc hemorrhage in low-tension glaucoma. Ophthalmology 1986;93:853-7.

9 Araie M, Sekine M, Suzuki Y, et al. Factors contributing to the progress of visual field damage in eyes with normal-tension glaucoma. Ophthalmology 1994; 101:1440-4.

10 Sonnsjo B, Krakau CET. Arguments for a vascular glaucoma etiology. Acta Ophthalmol 1993;71:433-44.

11 Cartwright MJ, Grajewski AL, Friedberg ML, et al. Immunologically-related disease and normal-tension glaucoma: a case-control study. Arch Ophthalmol 1992; 1 10:500-2.

12 Wax MB, Barrett DA, Pestronk A. Increased incidence of para-proteinemia autoantibodies in patients with normal-pressure glaucoma. Am J Ophthalmol 1994;117:561-8.

13 Harris A, Sergott RC, Spaeth GL, et al. Color Doppler analysis of ocular vessel blood velocity in normal-tension glaucoma. Am J Ophthalmol 1994:118:642-9.

14 Graham SL, Drance SM, Wijsman K, et al. Ambulatory blood pressure monitoring in glaucoma: the nocturnal dip. Ophthalmology 1995;102:61-9.

15 Meyer JH, Brandi-Dohrn J, Funk J. Twenty four hour blood pressure monitoring in normal tension glaucoma. Br J Ophthalmol 1996;80:864-7.

16 Meaney JF, Eldridge PR, Dunn LT, et al. Demonstration of neurovascular compression in trigeminal neuralgia with magnetic resonance imaging. Comparison with surgical findings in 52 consecutive operative cases. J Neurosurg 1995;83:799-805.

17 Nagahiro S, Takada A, Matsukado Y, et al. Microvascular decompression for hemifacial spasm. Patterns of vascular compression in unsuccessfully operated patients. J Neurosurg 1991;75:388-92.

18 Ohtsuka K, Sone A, Igarashi Y, et al. Vascular compressive abducens nerve palsy disclosed by magnetic resonance imaging. Am J Ophthalmol 1996;122:416-19.

19 Nishioka T, Kondo A, Suga K. Progressive blurring of vision in both eyes. Lancet 1995;346:1402.

20 Guyer DR, Miller NR, Long DM, et al. Visual function following optic canal decompression via craniotomy. J Neurosurg 1985;63:631-8.

21 Adams CB. Microvascular compression: an alternative view and hypothesis. J Neurosurg 1989;57:1-12.

22 Colapinto EV, Cabeen MA, Johnson LN. Optic nerve compression by dolicho ectatic internal carotid artery: case report. Neurosurgery 1996;39:604-6.

23 Jacobson DM. Symptomatic Compression of optic nerve by the carotid artery. Clinical profile of 18 patients with 24 affected eyes identified by magnetic resonance imaging. Ophthalmology 1999;106:1994-2004.

24 Golnik KC, Hund PW, Stroman GA, et al. Magnetic resonance imaging in patients with unexplained optic neuropathy. Ophthalmology $1996 ; 103: 515-20$

25 Plotnik JL, Kansupada KB, Kalenak JW, et al. Use of magnetic resonance angiography and clinical testing to evaluate diseases that may mimic normal tension glaucoma. ARVO abstracts. Invest Ophthalmol Vis Sci 1993;34(4, suppl): 1286

26 Gutman I, Melaned S, Ashkenazi I, et al. Optic nerve compression by carotid arteries in low-tention glaucoma. Graefes Arch Clin Exp Ophthalmol 1993;231:711-17

27 Stroman GA, Stewart WC, Golnik KC, et al. Magnetic resonance imaging in patients with low-tension glaucoma. Arch Ophthalmol 1995;113:168-72.

28 Umihara J, Oguchi K, Kurimoto Y, et al. Optic nerve compression by the internal carotid artery in patients with normal tension and high tension glaucoma. Br J Ophthalmol 1999:83:1307.

29 The Japan Glaucoma Society. The Japan Glaucoma Society guidelines for glaucoma. Nippon Ganka Gakkaizasshi 2003;107:125-57.

30 Jacobson DM, Warner JJ, Broste ST. Optic nerve contact and compression by carotid artery in asymptomatic patients. Am J Ophthalmol 1997; 123:677-83

31 Trobe JD, Glaser JS. Quantitative perimetry in compressive optic neuropathy and optic neuritis. Arch Ophthalmol 1978;96:1210-16.

32 Manor RS, Ouaknine GE, Matz S, et al. Nasal field loss with intracranial lesions of the optic nerve pathways. Am J Ophthalmol 1980;90:1-10.

33 Bianchi-Marzoli S, Rizzo J lii, Brancato R, et al. Quantitative analysis of optic disc cupping in compressive optic neuropathy. Ophthalmology 1994; 102:436-40.

34 Kalenak JW, Kosmorsky GS, Hassenbusche SJ. Compression of the intracranial optic nerve mimicking unilateral normal tension glaucoma. J Clin Neuro-ophthalmol 1992;12:230-5.

35 Greenfield DS, Siatkowski RM, Glaser JS, et al. The cupped disc. Who needs neuroimaging? Ophthalmology 1998;105:1866-74. 
36 Carter CJ, Brooks FD, Doyle DE, et al. Investigation into a vascular etiology for low-tension glaucoma. Ophthalmology 1990;97:49-55.

37 Stewart WC, Reid KK. Incidence of systemic and ocular disease that may mimic low-tension glaucoma. J Glaucoma 1992;1:27-31.

38 Jacobson DM, McCanna TD, Layde PM. Risk factors for ischemic ocular motor nerve palsies. Arch Ophthalmol 1994;1 12:961-6.
39 Shiose $Y$, Komuro $K$, Itoh $T$, et al. New system for mass screeing of glaucoma, as a part of automated multiohasic health testing service. Jpn J Ophthalmol $1981 ; 25: 160-77$

40 Ahmed IKA, Feldman F, Kucharczyk W, et al. Neuroradiologic screening in normal-pressure glaucoma: study results and literature review. J Glaucoma 2002;11:279-86

\section{Committee on Publication Ethics Seminar 2005 \\ Friday 11 March 2005, 9.30 am - 5 pm, BMA House, London}

This year's seminar will focus on COPE's new Code of Conduct for Editors and interactive workshops on common ethical and editorial dilemmas. The seminar is for editors, authors, and all those interested in increasing the standard of publication ethics.

The Code aims to set a new basic standard for the ethical conduct of editors and sets out guidelines for quality and correcting the record, standing by decisions made, ethics committee approval, consent for publication confidentiality of submitted material, guidance to authors, pursuing misconduct, relationship to publishers, owners, and advertisers, and conflict of interest. The code also creates a mechanism to refer a complaint to COPE if an editor has breached the code.

The seminar will include:

- The new Code of Conduct for Editors

- Dr lona Heath, Chair BMJ Ethics Committee-research, audit, and ethics committee approval

- COPE's new website-full text and keyword searching for COPE's advice on specific issues, for example research misconduct, conflict of interest, and deception

- Interactive workshops-common ethical and editorial dilemmas for editors

- Opportunities to network with other editors and share your experiences and challenges

The seminar is free for COPE members and $£ 30.00$ for non-members. Numbers are limited and early booking is advisable. For registrations or more information please contact Sam Knottenbelt at cope@bmigroup.com or call 0207383 6602. For more information on COPE see www.publicationethics.org.uk/ 